\title{
Monitores da disciplina Anatomia Humana desenvolvem material didático durante a pandemia da Covid-19
}

\author{
Monitors of Human Anatomy develop teaching material during the Covid-19 pandemic \\ Los monitores de disciplina desarrollan material didáctico de Anatomía Humana durante la \\ pandemia Covid-19
}

Giovana Geraldini Chermont ${ }^{1}$, Ana Beatriz de Fatima Pereira Souza ${ }^{1}$, Carlos André dos Reis Ursulino Soares $^{1}$, Carolina da Silva Bachini ${ }^{1}$, Fabrício Orellana Versolato de Abreu ${ }^{1}$, Felipi Harrison Teixeira Dutra $^{1}$, Giovana Santin Torres ${ }^{1}$, Henrique Souza Camoiço ${ }^{1}$, Lucas Giovani Bin ${ }^{1}$, Lucas Rodrigues Santa Cruz ${ }^{1}$, Luís Otávio Silva ${ }^{1}$, Mateus Scaliante Melo ${ }^{1}$, Luana Rossato ${ }^{1}$, Silvia Cristina Figueira Olinto ${ }^{1 *}$.

\section{RESUMO}

Objetivo: Descrever a experiência de monitores da disciplina Anatomia Humana do curso de Medicina da Universidade Federal da Grande Dourados (UFGD), que após o cancelamento de aulas presenciais ocasionadas pela pandemia do SARS CoV2 - Covid 19, elaboraram um material didático complementar para ser utilizado à distância. Relato de experiência: O material confeccionado contém uma breve descrição sobre todos os conteúdos abordados na disciplina, casos clínicos, imagens cadavéricas para a identificação das principais estruturas práticas e as relacionadas aos casos clínicos, bem como questões gerais sobre cada assunto. Considerações finais: A experiência permitiu que os alunos do curso de Medicina revisassem todo o conteúdo abordado na disciplina e desenvolvessem um material complementar utilizando metodologias ativas para a correlação da Anatomia Humana com a prática profissional. Destaca-se o benefício do desenvolvimento do material para o ensino remoto da disciplina, bem como sua utilização durante o retorno das aulas presenciais na Universidade.

Palavras-chave: Medicina, Material complementar, Ensino online, Ensino-Aprendizagem, Metodologia ativa.

\begin{abstract}
Objective: Describe an experience report of monitors of the discipline Human Anatomy of Medical course at the Federal University of Grande Dourados (UFGD), which, after the cancellation of face-to-face classes caused by the SARS CoV2 - Covid 19 pandemic, elaborated a complementary didactic material to be used at a distance. Experience report: The material produced contains a brief description of all the contents of the discipline, clinical cases, cadaverous images for the identification of the main practical structures and as related to clinical cases as well as general questions on each subject. Final considerations: The experience for medical students to review the entire content of the discipline and develop complementary material using active methodologies for the correlation of Human Anatomy with professional practice. The benefit of developing the material for the remote teaching of the discipline and its use during the return of on-site classes at the University stands out.
\end{abstract}

Keywords: Medicine, Complementary material, Online teaching, Teaching-learning, Active methodology.

\section{RESUMÉN}

Objetivo: Describir un relato de experiencia de monitores de la disciplina Anatomía Humana del curso de Medicina de la Universidad Federal de Grande Dourados (UFGD), que, luego de la cancelación de clases presenciales provocada por la pandemia de SARS CoV2 - Covid 19, elaboró un material didáctico complementario para ser utilizado a una distancia. Informe de experiencia: El material elaborado contiene una breve descripción de todos los contenidos cubiertos en la disciplina, casos clínicos, imágenes cadavéricas para la identificación de las principales estructuras prácticas y las relacionadas con los casos clínicos, así como cuestiones generales sobre cada tema. Consideraciones finales: La experiencia permitió a los estudiantes de medicina revisar todo el contenido de la disciplina y desarrollar material complementario utilizando metodologías activas para la correlación de la Anatomía Humana con la práctica profesional. Se destaca el beneficio de desarrollar material para la enseñanza a distancia de la disciplina y su uso durante el regreso de las clases presenciales en la Universidad.

Palabras clave: Medicina, Material complementario, Enseñanza online, Enseñanza-Aprendizaje, Metodología activa.

1 Universidade Federal da Grande Dourados, Dourados - MS. *E-mail: silviafigueira@ufgd.edu.br 


\section{INTRODUÇÃO}

A Anatomia Humana é a ciência que estuda macro e microscopicamente o desenvolvimento e a constituição dos seres organizados. Constitui um ramo da biologia cuja compreensão é fundamental para a boa prática de qualquer profissional da área da saúde (DANGELO JG e FATTIN CA, 2011).

O estudo da Anatomia sempre exerceu fascínio sobre os homens, conhecer e desvendar as estruturas constituintes do corpo sempre estimulou a curiosidade humana. Apesar de sua significativa importância, por muitos séculos diversas barreiras culturais e religiosas dificultaram o avanço dessa ciência, uma vez que o corpo era considerado inviolável. Muitas das descrições existentes reportavam dissecações feitas em animais, como as descritas por Galeno no sec. II dC. Portanto, era comum anatomistas recorrerem a meios ilícitos como roubo de túmulos, rapto de corpos e até mesmo assassinato, com o intuito de obterem acesso a um conhecimento mais fidedigno. Mesmo com a criação de leis que amparassem esse estudo, o preconceito ligado a tal prática permaneceu enraizado durante vários anos (GHOSH SK, 2015).

André Vesalio ajudou a corrigir noções equivocadas sobre descrições anatômicas que prevaleciam desde a Antiguidade. Através das dissecações de cadáveres marcou a época dividindo a Anatomia em antes e depois de seus estudos, motivo pelo qual foi consagrado como "pai da anatomia cientifica moderna" (TUBBS RI, et al., 2018).

No século XIX demonstrou-se a necessidade dos conhecimentos anatômicos para a prática clínica e cirúrgica. Atualmente, a ciência é considerada como alicerce para o estudo de todas as disciplinas clínicas. A identificação das estruturas que constituem o corpo humano, nas mais diferentes situações, com precisão e agilidade é de suma importância, uma vez que a cada momento as possibilidades de recuperação do paciente podem sofrer modificações. Assim, o estudo da ciência é fundamental para que os pacientes sejam beneficiados através de cuidados mais específicos e assertivos promovidos pelo melhor entendimento do corpo humano. Portanto, verifica-se que se o profissional possuir conhecimento anatômico humano adequado, o mesmo proporcionará um atendimento diferenciado e eficaz no diagnóstico assim como na intervenção (RODRÍGUEZ-HERRERA R, et al., 2019

O conhecimento acerca das estruturas corporais, de suas funções e inter-relações, é adquirido mediante aprendizagem completa e interativa. Tal área do saber fornece subsídios para uma prática médica segura aos profissionais da área da saúde. Aulas teóricas, práticas ministradas em laboratórios que dispõem de cadáveres dissecados, a utilização de projeções de vídeos e de imagens são métodos comumente utilizados (DARRAS KE, et al., 2019).

Entretanto, deficiências quanto ao conhecimento anatômico ainda persistem, o que sinaliza a necessidade de ferramentas educacionais mais ativas e distintas, caracterizando um diferencial no processo de ensinoaprendizagem, possibilitando maiores associações entre informações adquiridas na graduação e o exercício da medicina. Portanto, a produção de material didático alternativo utilizando metodologias ativas é de grande valia como método complementar ao processo ensino-aprendizagem (TAYYEM R, et al., 2019).

Nas instituições de ensino superior, a monitoria é uma prática que incentiva a inserção dos alunos no meio acadêmico. A origem da palavra monitoria possui intima ligação com o sistema educacional. Com relação a sua história, a instituição do monitor reporta-se à Antiguidade Clássica, nesse período, era o pedagogo que desempenhava as funções da monitoria. Foram instituídas com o objetivo de auxiliar os alunos com dificuldade de aprendizagem em cursos com altos índices de reprovação. Para a escolha dos monitores, eram realizados concursos no intuito de selecionar os alunos mais aptos para a realização da monitoria. As atividades desenvolvidas eram consideradas como aulas particulares, porém realizadas em grupo (DANTAS OM, 2014).

Atualmente a seleção obedece a critérios utilizados pelo professor da disciplina, o qual utiliza-se de recursos como avaliações teórico-práticas e/ou desempenho na disciplina. Com o seu emprego, a monitoria ganhou cada vez mais espaço no contexto da realidade educacional das instituições de Ensino Superior uma vez que a sua prática permite abranger vários aspectos importantes da prática pedagógica (BOTELHO LV, et al., 2018). 
A monitoria é uma estratégia que está prevista nos regimentos das instituições e nos projetos pedagógicos institucionais. Sua prática permite a potencialização do ensino de graduação através da participação dos alunos como mediador da aprendizagem dos colegas. Para tal, faz-se necessário dedicação, interesse além de disponibilidade dos envolvidos. É uma atividade recompensadora e que compreende as necessidades dos acadêmicos, uma vez que a fonte do conhecimento deriva dos próprios discentes, coordenados por um professor da área para orientação (FRISON LMB, 2016).

Em meio aos obstáculos impostos pela pandemia do SARS CoV2 - Covid 19, as inovações e adaptações dos métodos de ensino de Anatomia demonstraram ser extremamente necessárias. As dinâmicas tradicionais de ensino foram obrigadas a se reestruturar em virtude do distanciamento social, o que propiciou 0 despontamento de novas modalidades educacionais (GUSSO HL, et al., 2020).

Mediante o exposto, o presente trabalho relata a experiência de monitores da disciplina Anatomia Humana na produção de material didático pedagógico, durante o cancelamento das aulas presenciais provocado pela pandemia do SARS CoV2 - Covid 19.

\section{RELATO DE EXPERIÊNCIA}

Trata-se de um estudo descritivo, do tipo relato de experiência, realizado por monitores da disciplina Anatomia Humana I, ofertada no $1^{\circ}$ período do curso de graduação em medicina da UFGD. A ideia de elaborar o material de ensino complementar para a disciplina de Anatomia Humana surgiu durante o período em que houve a paralização das atividades presenciais da disciplina em virtude da pandemia provocada pelo SARS CoV2 - Covid 19. O intuito inicial foi produzir um material que pudesse ser utilizado à distância e que complementasse o ensino prático bem como teórico da disciplina.

A produção do material didático foi efetuada ao longo do $1^{\circ}$ e $2^{\circ}$ semestres de 2020. Semanalmente foram realizadas reuniões por meio da plataforma digital Google Meet para a orientação de todas as etapas até a produção final do material e artigo final. As atividades realizadas foram englobadas em 2 grandes etapas, descritas a seguir:

$\mathrm{Na}$ etapa 1 foi realizada a revisão de todos os conteúdos teórico-práticos ofertados pela disciplina Anatomia Humana I (Quadro 1).

Quadro 1 - Conteúdo programático da disciplina Anatomia Humana para o $1^{0}$ período do Curso de Medicina.

\begin{tabular}{|c|c|}
\hline SEGMENTOS & CONTEÚDO \\
\hline INTRODUÇÃO À ANATOMIA & $\begin{array}{l}\text { História; Métodos para estudo; Terminologia anatômica; posição } \\
\text { anatômica; Planos anatômicos; termos: relação e comparãa, } \\
\text { lateralidade, movimento, abreviações, variações anatômicas; Tegumento } \\
\text { comum; fáscias, compartimentos fasciais, bolsas e espaços virtuais; } \\
\text { sistemas corporais. }\end{array}$ \\
\hline TÓRAX & $\begin{array}{l}\text { Parede torácica: esqueleto, aberturas, articulações, movimentos, } \\
\text { músculos, fáscia, nervos, vascularização, mamas; vísceras da cavidade: } \\
\text { pleuras; mediastino, pericárdio, coração e grandes vasos; mediastinos: } \\
\text { superior, posterior e anterior. }\end{array}$ \\
\hline MEMBROS INFERIORES & $\begin{array}{l}\text { Considerações gerais; desenvolvimento; ossos; fáscia, vasos e nervos } \\
\text { cutâneos; postura e marcha; coxa e regiâo glútea; fossa poplítea; perna; } \\
\text { pé; articulações. }\end{array}$ \\
\hline MEMBROS SUPERIORES & $\begin{array}{l}\text { Considerações gerais; comparação entre os membros superiores e } \\
\text { inferiores; ossos, estruturas superficiais, músculos; axila; braço: } \\
\text { músculos, artéria braquial, veias, nervos e fossa cubital. }\end{array}$ \\
\hline CABEÇA & $\begin{array}{l}\text { Crânio: considerações gerais; vistas: frontal, lateral, occipital, superior } \\
\text { (vertical); bases: externa e interna; paredes da cavidade craniana; } \\
\text { estrutura do corpo cabeeludo; meninges cranianas: dura-máter, } \\
\text { leptomeninge aracnoíde-máter e pia-máter); espaços meníngeos; } \\
\text { encéfalo: partes, sistema ventricular, suprimento arterial, drenagem } \\
\text { venosa; face: músculos da face e do couro cabeludo, nervos, } \\
\text { vascularização superficial da face e do couro cabeludo; glândula } \\
\text { parótida; órbita regiâo orbital e bulbo do olho: pálpebras e aparelho } \\
\text { lacrimal, bulbo do olho, músculos extrínsecos, nervos e vascularização } \\
\text { da órbita; regiâo temporal: fossas temporal e infratemporal. }\end{array}$ \\
\hline PESCOÇO & $\begin{array}{l}\text { Ossos e fáscias; estruturas superficiais: regiões cervicais; estruturas } \\
\text { profundas; vísceras e vasos linfáticos. }\end{array}$ \\
\hline
\end{tabular}

Fonte: Chermont GG, et al., 2021. 
$\mathrm{Na}$ etapa 2 foi realizada a seleção e adaptação de casos clínicos que contemplassem todos os tópicos da disciplina, utilizando como referência bibliográfica o livro "Anatomia Clínica Baseada em Problemas" (PEZZI LHA, 2007). Além do livro, foram utilizados artigos científicos que descreviam casos clínicos que englobassem as estruturas abordadas. Precedendo o início de cada um dos casos, textos curtos foram redigidos com o intuito de descrever as principais características de cada conteúdo abordado. Em seguida, foram selecionadas imagens cadavéricas do Guia de Anatomia Asclépio (2011) disponível em: http://guiadeanatomia.com/anatomia.html.

Questões foram formuladas e/ou adaptadas oportunizando a realização de futuras discussões ao final de cada atividade. Nas questões relacionadas com os casos clínicos destacou-se uma pergunta sobre a estrutura anatômica comprometida ou a que determinado corpo estranho estava alojado. A sugestão de confecção de uma tabela com a citação das estruturas anatômicas e suas funções foi adaptada do artigo "Utilização de Metodologia Ativa de Ensino nas Aulas Práticas de Anatomia" publicado por Carvalho CAF (2017). Para finalizar o processo de confecção do material, foram elaborados gabaritos referentes a cada atividade proposta.

\section{DISCUSSÃO}

A Anatomia Humana é considerada a "base das ciências médicas". Seu estudo permite compreender a organização dos sistemas através do estudo e reconhecimento da morfologia e função dos órgãos. Portanto, é de sua importância que discentes do curso de Medicina adquiriram conhecimentos anatômicos para a construção de uma base sólida para a futura prática profissional (SALBEGO C, et al., 2015).

O exercício da monitoria representa uma oportunidade para o estudante desenvolver habilidades relacionadas à docência, aprofundar conhecimentos na área específica além de contribuir com o processo de ensino-aprendizagem de alunos que estão cursando a disciplina. Representa uma ferramenta eficaz pois permite que o discente aprofunde seus conhecimentos na disciplina, compartilhe suas experiências e desenvolva estratégias facilitadoras do processo ensino-aprendizagem. É uma atividade recompensadora e que compreende as necessidades dos acadêmicos, uma vez que a fonte do conhecimento deriva dos próprios discentes, coordenados por um professor da área para orientação (DANTAS OM, 2014).

O desenvolvimento do material permitiu que os monitores continuassem com o estudo da disciplina, através da revisão de conceitos anatômicos teóricos, bem como práticos, correlacionando-os com a prática clínica através do estudo integrado com os casos clínicos e imagens cadavéricas. A utilização de imagens cadavéricas permitiu que incluíssemos questões de caráter prático correlacionando a disciplina com as questões apresentadas em cada caso clínico. Nesse sentido, a utilização da metodologia permitiu vincularmos a teoria com à prática da disciplina, enfatizando situações deparadas rotineiramente na prática dos futuros profissionais médicos.

Segundo Macedo KDS, et al. (2018) as metodologias ativas utilizam a problematização como estratégia de ensino-aprendizagem, tendo como objetivo a motivação do discente. Quando o aluno depara-se com uma situação-problema, ele precisará refletir, relacionar a sua história e passar a dar ressignificado as suas descobertas. Portanto, a utilização da estratégia permite ao aluno condições para identificar e solucionar as dúvidas, proporcionando benefícios durante o seu desenvolvimento das atividades.

A problematização e a aprendizagem baseada em problemas oferecem alternativas de ensino dos conteúdos teórico-práticos (COLARES MAM, et al., 2019). A leitura e discussão dos casos clínicos permite que os alunos tenham um primeiro contato com patologias ou situações que acometem os diferentes tipos de órgãos, permitindo que o conhecimento adquirido seja correlacionado a futura prática clínica (ARSLANOE, 2014).

Métodos parecidos, como os de Eseonu O, et al. (2013), demonstraram estatisticamente maior aceitação e melhor desempenho em avaliações tradicionais pelos alunos. Isso confirma a viabilidade dos casos clínicos em associação com o método tradicional de ensino de maneira complementar. Benefícios vindos desses métodos como a aproximação do aluno à realidade da profissão são previstos também, uma vez que, 
conforme Miolo SB e Fedosse E (2020), a parte clínica dá força e significado ao aprendizado da Anatomia que, na maioria das vezes, pode ser muito descritiva e pouco assimilativa. $O$ aluno é encorajado a procurar em livros, artigos científicos para responder as respostas das questões elaboradas; construindo assim uma forma ativa na construção do aprendizado (PARANHOS VD e MENDES MM, 2010).

Pather N, et al. (2020) demonstraram experiências semelhantes as descritas no presente relato. Nas aulas remotas da disciplina Anatomia Humana em países como Austrália e Nova Zelândia utilizou-se como metodologia discussões em pequenos grupos nas mídias digitais de streaming. A disponibilidade de material didático online, é necessária, e vai ao encontro do desenvolvimento de novos recursos online, um dos benefícios apontados por Longhurts GJ, et al. (2020) quando se refere às adaptações no ensino de Anatomia no Reino Unido e na República da Irlanda durante a pandemia de Covid-19.

Portanto, o uso de metodologias ativas permite que o aluno experimente diferentes opções de práticas pedagógicas, tornando o ensino mais próximo a sua realidade, o discente torna-se o autor do próprio conhecimento. Além disso, a utilização de metodologias ativas estimula o aluno a ter um pensamento crítico bem como reflexivo, tornando o processo de ensino-aprendizagem vantajoso quando comparado somente com o modelo tradicional de ensino (FORNAZIERO CC, et al., 2010; NEVES MVS, 2010).

A experiência permitiu que os monitores desenvolvessem um material didático direcionado ao ensino remoto, contribuindo com processo de ensino-aprendizagem da disciplina no momento da pandemia provocada do SARS CoV2 - Covid 19. Apesar do objetivo inicial ter sido a utilização do material à distância, seu uso poderá ser estendido a outros momentos como meio complementar de ensino da ciência Anatomia Humana. Assim, a aplicação do referido material apresenta grande potencial de impacto como método complementar para estudantes do $1^{\circ}$ período do curso de Medicina.

O desenvolvimento do material permitiu que os monitores revisassem o conhecimento anatômico, confeccionassem um material didático utilizando casos clínicos como metodologia ativa de ensino, abordando todos os tópicos da disciplina. A utilização de imagens cadavéricas permitiu que o ambiente do laboratório de Anatomia Humana fosse integrado ao trabalho, agregando assim, mais elementos para a correlação da disciplina com a clínica. A aplicação do material à distância não inviabilizará que seu uso seja realizado como estudo complementar no retorno das aulas presenciais. O desenvolvimento do material abre caminho para futuras elaborações de materiais didáticos pedagógicos que complementem e correlacionem a disciplina com a futura prática do profissional médico.

\section{AGRADECIMENTOS}

Agradecemos a professora Dra. Daniela Cristina de Oliveira Silva, Professora da Disciplina de Anatomia da Universidade Federal de Uberlândia (ICBIM, UFU), os acadêmicos da Faculdade de Medicina da Universidade Federal de Uberlândia (UFU): Alan Bartasson Ferreira Rosa, Pedro Zerri David e também ao Técnico do Laboratório de Anatomia (ICBIM, UFU) Lázaro Antônio dos Santos, por terem permitido a utilização de imagens cadavéricas obtidas do Asclépio Atlas de Anatomia (http://guiadeanatomia.com/anatomia.html).

\section{REFERÊNCIAS}

1. ARSLAN OE. Region vs. system-based anatomy: efficacy and implementation. American International Journal of Biology, 2014;2(3):1-23.

2. BOTELHO LV, et al. Monitoria acadêmica e formação profissional em saúde: uma revisão integrativa. Arquivos Brasileiros de Ciências Da Saúde, 2019; 44(1):67-74.

3. CARVALHO CA. Utilização de Metodologia Ativa de Ensino nas Aulas Práticas de Anatomia. Revista de Graduação USP, 2017; 2(3):117-121.

4. COLARES MAM, et al. Metodologias de ensino de anatomia humana: estratégias para diminuir as dificuldades e proporcionar um melhor processo de ensino-aprendizagem. Arquivos do Mudi, 2019; 23 (3): 140-160.

5. DANGELO JG, FATTINI CA. Anatomia Humana: Sistêmica e Segmentar. 3a ed. São Paulo: Atheneu, 2011; 757p.

6. DANTAS OM. Monitoria: fonte de saberes à docência superior.Revista Brasileira de Estudos Pedagógicos,2014; 95 (241): 567-589.

7. DARRAS KE, et al. Integrated Virtual and Cadaveric Dissection Laboratories Enhance First Year Medical Students' Anatomy Experience: A Pilot Study. BMC Medical Education, 2019; 19 (366): 1-6. 
8. ESEONU O, et al. Case-based anatomy teaching: a viable alternative? The Clinical Teacher, 2013; 10 (4):236-241.

9. FORNAZIERO CC. O ensino da anatomia: integração do corpo humano e meio ambiente. Revista Brasileira de Educação Médica, 2010; 34 (2):290-297.

10. FRISON LMB. Monitoria: uma modalidade de ensino que potencializa a aprendizagem colaborativa e autorregulada. Pro-Posições, 2016; 27 (1): 133-153.

11. GHOSH SK. Human cadaveric dissection: a historical account from ancient Greece to the modern era. Anatomy \& Cell Biology, 2015; 48 (3): 153.

12. GUIA DE ANATOMIA ASCLÉPIO. 2014. Disponível em: http://guiadeanatomia.com/anatomia.html.

13. GUSSO HL, et al. Ensino superior em tempos de pandemia: diretrizes à gestão universitária. Educação\& Sociedade, 2020; 41:1-26.

14. LONGHURST GJ, et al. Strength, Weakness, Opportunity, Threat (SWOT) Analysis of the Adaptations to Anatomical Education in the United Kingdom and Republic of Ireland in Response to the Covid-19 Pandemic. Anatomical Science Education, 2020; 3:298-308.

15. MIOLO SB, FEDOSSE E. Tutoring and preceptory in multiprofessional residence programs in basic care: a necessary dialogue. Research SocietyandDevelopment, 2020; 9(3): 25.

16. MACEDO KDS, et al. Metodologias ativas de aprendizagem: caminhos possíveis para inovação no ensino em saúde Escola Anna Nery, 2018; 22(3):1-9.

17. NEVES MVS. Uma nova proposta no ensino da Anatomia Humana: desafios e novas perspectivas. $2010.39 \mathrm{f}$. Dissertação (Mestrado Profissional em Ensino de Ciências da Saúde e do Meio Ambiente) - Centro Universitário de Volta Redonda, Volta Redonda, 2010.

18. PARANHOS VD, MENDES MM. Competency-based curriculum and active methodology: perceptions of nursing students. Revista Latino-Americana de Enfermagem, 2010; 18 (1):109-115.

19. PATHER N, et al. Forced Disruption of Anatomy Education in Australia and New Zealand: An Acute Response to the Covid-19 Pandemic, 2020. Anatomical Sciences Education; 13( 3): 284-300.

20. PEZZI LHA, et al. Anatomia Clínica Baseada em Problemas. $1^{a}$ ed. Rio de Janeiro: Guanabara Koogan, 2017.

21. RODRIGUEZ-HERRERA R, et al. La Anatomía Humana como Disciplina Indispensable en la Seguridad de los Pacientes. International Journal of Morphology, 2019; 37(1):241-250.

22. SALBEGOC, et al. Percepções Acadêmicas sobre o Ensino e a Aprendizagem em Anatomia Humana, Revista Brasileira de Educação Médica, 2015;39 (1):23-31.

23. TAYYEM R, et al. Medical Students Perception of Current Undergraduate Anatomy Teaching. International Journal of Morphology, 2019; 37 (3):825-829.

24. TUBBS R, et al. The influence of ancient Greek thought on fifteenth century anatomy: Galenic influence and Leonardo da Vinci. Child's Nervous System: ChNS: Official Journal of the International Society for Pediatric Neurosurgery, 2017; 34 (6): 1095-1101. 